\title{
SOX11 and FAK participate in the stretch-induced mechanical injury to alveolar type 2 epithelial cells
}

\author{
MINGXING FANG ${ }^{1,2}$, TIELING XU ${ }^{3}$, SHUJUAN FAN $^{1}$, NA LIU $^{4}$, LUPING LI ${ }^{5}$, JUNXIA GAO ${ }^{1}$ and WENBIN LI ${ }^{1}$ \\ ${ }^{1}$ Department of Pathophysiology, Neuroscience Research Center, Hebei Medical University, Shijiazhuang, \\ Hebei 050017; ${ }^{2}$ Department of Intensive Care Medicine, The Third Hospital of Hebei Medical University, \\ Shijiazhuang, Hebei 050051; ${ }^{3}$ Department of Emergency, Hebei General Hospital; ${ }^{4}$ Department of Emergency, \\ The Fourth Hospital of Hebei Medical University, Shijiazhuang, Hebei 050000; ${ }^{5}$ Experimental Center, \\ The Third Hospital of Hebei Medical University, Shijiazhuang, Hebei 050051, P.R. China
}

Received July 3, 2020; Accepted November 3, 2020

DOI: $10.3892 /$ ijmm.2020.4795

\begin{abstract}
The aim of the present study was to explore the potential role of SOX11 in the stretch-induced mechanical injury to alveolar type 2 epithelial (AT2) cells. A cell stretch (CS) test was used to induce mechanical injury to primary cultured AT2 cells. Wound healing, adhesion, cell viability assays and flow cytometry were performed to evaluate the migration, adhesion, viability and apoptosis of AT2 cells. Changes in the invasive ability of AT2 cells were detected using a Transwell invasion assay. To further explore the underlying molecular mechanisms, reverse transcription-quantitative PCR and western blot analysis were used to assess the expression levels of SOX11, FAK, Akt, caspase-3/8, p65 and matrix metalloproteinase (MMP)7. Co-immunoprecipitation (Co-IP) and luciferase reporter assays were used to detect the interaction between SOX11 and FAK. CS reduced the invasion, migration and adhesion, and increased the apoptosis of AT2 cells. It also resulted in the downregulation of SOX11 and FAK expression in AT2 cells. The overexpression of SOX11 reversed these changes, whereas the knockdown of SOX11 aggravated the deterioration of the aforementioned biological behaviors and the apoptosis of the AT2 cells following CS. The overexpression of SOX11 upregulated the FAK and Akt expression levels, and downregulated caspase-3/8 expression, whereas the silencing of SOX11 reversed these changes following CS. Furthermore, the effects of SOX11 overexpression were inhibited by FAK antagonism. The results of Co-IP demonstrated that SOX11 and FAK were bound together, and that the expression of FAK was significantly increased in the
\end{abstract}

Correspondence to: Professor Wenbin Li, Department of Pathophysiology, Neuroscience Research Center, Hebei Medical University, 361 Zhongshan East Road, Shijiazhuang, Hebei 050017, P.R. China

E-mail: liwbsjz@163.com

Key words: alveolar type 2 epithelial cells, cell stretch, SOX11, FAK, ventilator induced lung injury
SOX11 overexpression group. Luciferase assays revealed that the luciferase activity and the mRNA expression of FAK were significantly increased following transfection with pcDNA SOX11 and pGL3 FAK promoter. Co-IP and luciferase assays revealed that SOX11 directly regulated the expression of FAK. On the whole, the present study demonstrates that the downregulated expression of SOX11 and FAK are involved in the stretch-induced mechanical injury to AT2 cells. The overexpression of SOX11 significantly alleviates AT2 cell injury through the upregulation of FAK and Akt, and the inhibition of apoptosis. These findings suggest that the activation of SOX11 and FAK may be potential preventive and therapeutic options for ventilator-induced lung injury.

\section{Introduction}

Mechanical ventilation using a ventilator is an essential means of life support for patients with severe respiratory failure, such as acute respiratory distress syndrome. However, excess mechanical ventilation may result in ventilator-induced lung injury (VILI), which is the most common complication of mechanical ventilation (1). Several theories, such as barotrauma, volutrauma, atelectrauma and biotrauma have been proposed and, in particular, the biotrauma theory has now been expanded upon to illustrate the mechanisms underlying VILI (1). Amongst several biomolecules in the biotrauma theory involved in the pathogenesis of VILI, the Sex-determining gene on the $\mathrm{Y}$ chromosome related high mobility group box (SOX) and focal adhesion kinase (FAK) are gaining increasing attention as therapeutic targets for the treatment of lung diseases (2-5).

Several members of the SOX family are involved in the pathophysiological process of lung injury. Gross et al (6) found that changes in SOX18 expression were involved in endotoxin-induced acute lung injury. SOX9 exerts protective effects on lipopolysaccharide-induced lung fibroblasts, apoptosis and the expression of inflammatory factors (7). SOX11 has been shown to be involved in epithelial-mesenchymal interactions and is associated with lung development and pulmonary injury (8). SOX11 can positively regulate members of the FAK family, which is a subfamily of non-receptor protein tyrosine 
kinases and a key regulator of growth factor receptor- and integrin-mediated signals, and governs fundamental processes of cells under physiological and pathophysiological conditions through its kinase activity and scaffolding function $(9,10)$. The inhibition of FAK expression can lead to the destruction of the cell barrier and increase pulmonary vascular permeability of ischemic lung injury (11). Conversely, the increase in FAK expression may improve pulmonary vascular permeability caused by acute injury $(12,13)$, reduce the protein levels in bronchoalveolar lavage fluid and decrease necrosis and apoptosis of lung epithelial cells (14). In our previous studies, it was shown that the expression of SOX11 and FAK in alveolar epithelial cells in HMV-induced VILI in vivo was dysregulated in vivo (15) and in vitro (16). These findings suggest that the dysregulation of SOX11 and FAK serve an important role in the pathogenesis of VILI.

Shear stress resulting from alveolar overstretching at high pressures during artificial ventilation is the primary cause of VILI. Alveolar type 2 epithelial (AT2) cells produce pulmonary surfactants and participate in cell regeneration, which plays an important role in maintaining alveolar integrity (17). Therefore, in order to illustrate the role of AT2 cell injury in the pathogenesis of VILI and the role of SOX-FAK signals in this process, the present study investigated the effects of cell stretch (CS), which is used to simulate the shear stress of alveolar overstretching, on the biological behaviors of cells, including migration, adhesion, viability and apoptosis of AT2 cells, and the role of SOX/FAK signaling in this process, through the overexpression and knockdown of SOX11. Furthermore, to elucidate the molecular mechanisms downstream of SOX-FAK signaling, changes in the expression levels of Akt, caspase-3/8, p65 and matrix metalloproteinase (MMP)7 in AT2 cells following CS were also investigated.

\section{Materials and methods}

Ethics statement. The animal experiments were approved by the Committee of Ethics on Animal Experiments of Hebei Medical University (approval no. ILAS-PL-2010-004). All efforts were made to minimize the suffering of animals and the number of the animals used.

Experimental grouping and protocols. AT2 cells (details provided below) were randomly divided into 5 groups as follows: i) The sham group, cells were cultured in normal culture medium for $72 \mathrm{~h}$, corresponding to the culture time following transfection in the other groups, and then subjected to the sham treatments for CS; ii) CS group, AT2 cells were cultured for $72 \mathrm{~h}$ first and then underwent CS; iii) SOX11 overexpression group, AT2 cells were transfected with SOX11 plasmid and underwent CS $72 \mathrm{~h}$ following transfection with the SOX11 plasmid; iv) SOX11 plasmid + FAK antagonist group, AT2 cells were transfected with SOX11 plasmid and treated with 1.5 mM FAK antagonist (PF562271; cat. no. GC12174, Glpbio Technology, Inc., dissolved in DMSO) for $72 \mathrm{~h}$ and then subjected to CS; v) SOX11 siRNA group, AT2 cells were subjected to $\mathrm{CS}$ at $72 \mathrm{~h}$ following transfection with SOX11 siRNA.

Following CS or sham treatment, the AT2 cells were collected to evaluate the migratory ability using a wound healing assay, adhesion ability and viability using cell adhesion and viability assays. The proportion of apoptotic cells was evaluated by flow cytometry. Furthermore, the expression levels of SOX11, FAK, Akt, caspase-3/8, p65 and MMP7 were evaluated at the mRNA (only SOX11 and FAK) and protein levels by reverse transcription-quantitative PCR (RT-qPCR) western blot analysis following CS or sham treatment. To directly link the observed changes in the molecules with the protective effects of SOX11 against the mechanical injury to AT2 cells, changes in the levels of these molecules were assessed following CS. However, it is possible that these molecules may have been already activated and the activation continued to the time point when CS performed.

AT2 cell isolation and culture and identification. C57 mice supplied by the Chinese Academy of Medical Sciences were used in the present study. To isolate and culture AT2 cells, 140 neonatal mice born within $24 \mathrm{~h}$ were euthanized by an intraperitoneal injection of $3 \%$ pentobarbital sodium $(150 \mathrm{mg} / \mathrm{kg})$, and immersed in $75 \%$ alcohol for $2 \mathrm{~min}$. The lungs were collected and the trachea, macrovascular tissue and bronchus were removed and placed in pre-cooled PBS. The lung tissue was cut into $1-\mathrm{mm}^{3}$-thick sections after fully rinsing with PBS and then digested with trypsin $(1 \mathrm{~g} / \mathrm{l})$ for $5 \mathrm{~min}$ at $37^{\circ} \mathrm{C}$ after mixing well. The cell suspension was then collected and centrifuged at $12,000 \mathrm{x} \mathrm{g}$ for $3 \mathrm{~min}$ at room temperature. The cell pellet was re-suspended in DMEM containing $10 \%$ FBS to terminate digestion. The remaining lung tissue was then mixed with $2 \mathrm{ml}$ collagenase I $(1 \mathrm{~g} / \mathrm{l}$ containing $0.01 \mathrm{~g} / 1 \mathrm{DNase} \mathrm{I})$, and then incubated at $37^{\circ} \mathrm{C}$ for $15 \mathrm{~min}$. The cell suspension was collected and an equivalent volume of $10 \%$ FBS were added to terminate the digestion. The cell suspensions were merged and mixed well with a straw 50 times. The cell suspension was filtered using a filter 200 mesh screen and centrifuged at $12,000 \mathrm{x} \mathrm{g}$ for $5 \mathrm{~min}$ at room temperature twice. The supernatant was discarded and the precipitate was resuspended in an equivalent volume of 10\% FBS DMEM. Pneumonocyte suspensions were inoculated in a culture dish coated with mouse $\operatorname{IgG}$ and incubated for $45 \mathrm{~min}$ at room temperature. The liquid with non-adherent cells was collected and plated in another culture dish coated with mouse $\mathrm{IgG}$ at $37^{\circ} \mathrm{C}$ for $40 \mathrm{~min}$. The above-mentioned process was repeated twice. Finally, the non-adherent cells were collected and centrifuged at $12,000 \mathrm{x}$ g for $5 \mathrm{~min}$ twice at room temperature. The supernatant was then discarded. The cell pellets were resuspended in DMEM with 10\% FBS and the cell count was adjusted to $1 \times 10^{9} / 1$ and inoculated in 6-well plates. The AT2 cells were identified by morphological evaluation under a microscope (BX53, Olympus Corporation), and by immunofluorescence staining targeting LAMP and ABCA3, which are classical biochemical hallmarks of AT2 cells (Fig. S1).

The cell culture medium was replaced every 2 days, and the morphology and growth of the AT2 cells were observed using an inverted microscope (LX71, Olympus Corporation) every day. The AT2 cells pre-cultured for 3-5 days were used for experiments.

Immunofluorescence staining. AT2 cells plated on coverslips were rinsed with PBS, and then fixed with $4 \%$ paraformaldehyde 
for $15 \mathrm{~min}$ at room temperature. The AT 2 cells were then washed with PBS and exposed to $0.3 \%$ Triton X-100 at $37^{\circ} \mathrm{C}$ for $20 \mathrm{~min}$. After washing with PBS and blocking with $10 \%$ normal goat serum at $37^{\circ} \mathrm{C}$ for $30 \mathrm{~min}$, the AT2 cells were incubated with the mixture of primary antibodies against LAMP derived from rabbit (1:200, cat. no. Bs-1970R, lot no. A106217651, BIOSS) and ABCA3 derived from rabbit (1:200, cat. no. Bs-17588R, lot. no. AD101749, BIOSS) overnight at $4^{\circ} \mathrm{C}$. After washing 3 times with PBS, the AT2 cells were co-incubated with secondary antibodies, including $\mathrm{Cy} 3$ goat anti-rabbit IgG (1:100, cat. no. BA1032, lot no. BST15C09A15132, Wuhan Boster Biological Technology, Ltd.) at $37^{\circ} \mathrm{C}$ for $60 \mathrm{~min}$. DAPI was then used for staining with incubation in the dark for $5 \mathrm{~min}$. Subsequently, the coverslips were washed with PBS and coverslipped with fluorescent antifade mounting solution. Images were obtained by an investigator who was blinded to the experiment groups using a microscope (BX53, Olympus Corporation).

CS. CS was performed using a Flexercell FX-4000T cell stretch system equipped with a 25-mm BioFlex Loading station (Flexcell International). The AT2 cells were mounted in the Strain Unit of the equipment, and then exposed to CS for $4 \mathrm{~h}$ (frequency, $0.5 \mathrm{~Hz}$; time ratio of pull and relaxation, 1:1; amplitude, 20\%; 30 cycles per min) to mimic stretch-induced AT2 cell injury (11). The AT2 cells in the sham group were also placed in the equipment and underwent the same process apart from the stretching.

SOX11 overexpression and knockdown. A recombinant adenovirus-SOX11 plasmid (Addgene, Inc.) was purchased. The protocol for overexpression was performed as previously described (17). Briefly, mouse SOX11 cDNAs were subcloned into the pCMV-IRES-EGFP plasmid, and the IRES-eGFP sequence was removed to create pCMV-SOX11. The adenoviral vector and pCMV-SOX11 were then transfected into 293 T cells (Procell Life Science \& Technology Co., Ltd.), and the recombinant adenovirus-SOX11 was harvested from the cell lysate using the calcium phosphate precipitation method. In the present study, the SOX11 plasmid at a concentration of $50 \mathrm{nM}$ in the medium was transfected into the AT2 cells using poly plus transfection reagent (Polyplus-transfection SA) according to the manufacturer's protocol.

SOX11 siRNA and its scrambled probe (Santa Cruz Biotechnology, Inc.) were also purchased. The sequence of the SOX11 siRNA was 5'-GCTGACTACCCCGACTACAAG-3'. In the present study, the SOX11 siRNA or its scrambled probe $(40 \mathrm{nM})$ were transfected into the AT2 cells using Lipofectamine 2000 (Invitrogen; Thermo Fisher Scientific, Inc.) according to the manufacturer's protocol. RT-qPCR and western blot analysis were used to confirm the efficacy of transfection after $72 \mathrm{~h}$.

Wound healing assay. The migratory ability of the AT2 cells was evaluated using a wound healing assay. Following the treatment of each group, the cells were collected and incubated in 6-well plates for culture until the cells grew to $80 \%$ confluency in DMEM/F12 medium containing $10 \%$ fetal bovine serum (Gemini Bio Products) and 1\% penicillin-streptomycin (Gibco; Thermo Fisher Scientific, Inc.). Subsequently, a wound was scratched in the cell monolayer using a sterile pipette tip, and the plates were washed with PBS to remove debris. The remaining cells were allowed to grow in the wells in medium without fetal bovine serum for $72 \mathrm{~h}$. The gap distance was quantitatively evaluated and imaged at 0 and $72 \mathrm{~h}$ after creating the scratch. An inverted microscope (LX71, Olympus Corporation) and ImageJ software (ImageJ-Pro Plus 6.0, National Institutes of Health) were used to observe and calculate the percentage of wound closure.

Cell adhesion assay. For cell adhesion assay, the AT2 cells were collected immediately following the corresponding treatments in each group and seeded in fibronectin pre-coated 96-well plates $\left(50,000\right.$ cells/well), and cultured for $2 \mathrm{~h}$ at $37^{\circ} \mathrm{C}$ in DMEM supplemented with FBS (Gibco; Thermo Fisher Scientific, Inc.). Subsequently, the plates were washed with PBS buffer to remove any unattached cells, and subsequently blocked with $1 \% \mathrm{BSA}$ for $30 \mathrm{~min}$ at $37^{\circ} \mathrm{C}$. The cells were stained for $1 \mathrm{~h}$ at $37^{\circ} \mathrm{C}$ using a WST-1 assay kit (Roche Diagnostics) according to the manufacturer's protocol. The absorbance was measured at $690 \mathrm{~nm}$ using a multimode plate reader (BioTek Instruments, Inc.).

Cell invasion experiments. Matrigel stored at $-20^{\circ} \mathrm{C}$ was allowed to melt at $4^{\circ} \mathrm{C}$ overnight. Matrigel was diluted with pre-cooled serum-free DMEM medium to a final concentration of $1 \mathrm{mg} / \mathrm{ml}$, and $100 \mathrm{ml}$ diluted Matrigel were added to the bottom of the central chamber of a Transwell insert, and incubated at $37^{\circ} \mathrm{C}$ until it had polymerized. For gum reconstruction, $200 \mathrm{ml}$ DMEM were added to each well. After the cells were trypsinized and centrifuged at $10,000 \mathrm{x}$ g for $5 \mathrm{~min}$ at $4^{\circ} \mathrm{C}$ to remove the culture medium and washed with PBS, they were resuspended in serum-free medium and seeded on the upper chamber $(10,000$ cells per well) of the Transwell insert. Culture medium containing $10 \%$ FBS was added to the lower chamber and cultured at $37^{\circ} \mathrm{C}$. Subsequently, after culturing for $36 \mathrm{~h}$, the liquid in the upper chamber was discarded, the upper chamber was removed, and a cotton swab was used to wipe off the cells that had not passed through the cell membrane. Cells were fixed with $3.7 \%$ formaldehyde for $10 \mathrm{~min}$, stained with crystal violet (cat. no. 548-82-9, Biotopped) for $20 \mathrm{~min}$ at room temperature, and cells were observed under an inverted microscope (LX71, Olympus Corporation). A total of 3 fields of view were randomly selected, and the number of cells that had invaded was calculated using ImageJ software (ImageJ-Pro Plus 6.0, National Institutes of Health) for statistical analysis. Transwell chambers were purchased from Corning Co. Matrigel matrix $(5 \mathrm{mg} / \mathrm{ml})$ was purchased from Thermo Fisher Scientific, Inc.

Apoptosis assay. Flow cytometry was used to evaluate the apoptosis of the AT2 cells. Following the treatments, the AT2 cells were collected and washed with PBS, and then resuspended in $500 \mu \mathrm{l}$ binding buffer containing $5 \mu \mathrm{l}$ Annexin V-FITC and $10 \mu \mathrm{l}$ propidium iodide (Bio-Rad Laboratories, Inc.). Following incubation for $30 \mathrm{~min}$ in the dark at room temperature, the apoptotic ratio was measured using a FACScan flow cytometer (Cyto-Flex Beckman) according to the protocol provided with the Annexin V/PI kit.

$R T-q P C R$. The mRNA expression levels of SOX11 and FAK in the AT2 cells were evaluated by RT-qPCR. Following the 
treatments, the AT2 cells were collected and the total RNA was extracted using an RNeasy kit (Qiagen, Inc.) and cDNA was synthesized from $500 \mathrm{ng}$ total RNA using SuperScript (Invitrogen; Thermo Fisher Scientific, Inc.). Semi-quantitative levels of SOX11 and FAK mRNA were measured using a RT-qPCR system (cat. no. K2622, Thermo Fisher Scientific, Inc.) according to the manufacturer's protocol. The sequences of the primers used were as follows: GAPDH forward, 5'-AAT GGATTTGGACGCATTGGT-3' and reverse, 5'-TTTGCA CTGGTACGTGTTGAT-3'; SOX11 forward, 5'-CGAGCC TGTACGACGAAGTG-3' and reverse, 5'-AAGCTCAGGTCG AACATGAGG-3'; and FAK forward, 5'-CCATGCCCTCGA AAAGCTATG-3' and reverse, 5'-TGACGCATTGTTAAG GCTTCT-3'. PCR ( $3 \mathrm{~min}$ at $94^{\circ} \mathrm{C}$ and 35 cycles of $30 \mathrm{sec}$ at $94^{\circ} \mathrm{C}, 30 \mathrm{sec}$ at $58^{\circ} \mathrm{C}$ and $45 \mathrm{sec}$ at $72^{\circ} \mathrm{C}$ ) was performed in triplicate. Gene expression was calculated using the $2^{-\Delta \Delta \mathrm{Cq}}(18)$ method and normalized to GAPDH expression.

Western blot analysis. The protein expression levels of SOX11, FAK, Akt, caspase-3/8, p65 and MMP7 in the AT2 cells were evaluated by western blot analysis. Following the treatments, the AT2 cells were collected and lysed in RIPA lysis buffer containing protease inhibitor. Equal quantities of protein $(20 \mu \mathrm{g})$ were loaded on $8-10 \%$ SDS-gels, resolved using SDS-PAGE and electrotransferred to PVDF membranes (EMD Millipore). $\beta$-actin was used as the loading control. The membranes were then incubated with the primary antibodies overnight at $4^{\circ} \mathrm{C}$. The primary antibodies used were the following: Rabbit SOX11-polyclonal antibody (Cusabio; Ho926s, cat. no. CSB-PA899716; 1:3,000); rabbit-FAK-monoclonal antibody (Abcam; CR280473, cat. no. ab40794; 1:3,000); rabbit caspase-3-monoclonal antibody (Affinity Biosciences; $3253 \mathrm{u} 12$ cat. no. AF6311; 1:2,000); rabbit caspase-8 monoclonal antibody (Affinity Biosciences; 19u71; cat. no. AF6442; 1:2,500); mouse Akt monoclonal antibody (Affinity Biosciences; 19u71, cat. no. AF6261; 1:3,000); mouse phospho-Akt-monoclonal antibody (Epitomics; Abcam; YE112001, cat. no. 1085-1; 1:4,000); mouse MMP7-derived monoclonal antibody (ABclonal Biotech Co., Ltd.; 36490, cat. no. A0695; 1:2,000 dilution); mouse p65 monoclonal antibody (GeneTex; 40020, cat. no. GTX61793; 1:3,000 dilution) and rabbit â-actin monoclonal antibody (ABclonal Biotech Co., Ltd.; 9100026001, cat. no. AC026; 1:2,000 dilution). Subsequently, the membranes were incubated with anti-rabbit IgG (KPL, Inc. cat. no. 074-1506; lot no. $140740 ; 1: 3,000$ ), or anti-mouse IgG (Sino Biological Inc.; cat. no. H013FE2708; lot no. SSA007; 1:2,500). Signals were visualized using a Western Bright ECL kit (Bio-Rad Laboratories, Inc.). The integrative optical density (IOD) of the immunoreactive bands was measured using an Alpha Innotech AlphaImager 2200 (Alpha Image 2200, Alpha Technologies). The relative quantity of protein was expressed as the ratio of IOD value of target proteins to $\beta$-actin.

Co-immunoprecipitation (Co-IP). The transfected AT2 cells were solubilized in RIPA cell lysis buffer (Invitrogen; Thermo Fisher Scientific, Inc.) supplemented with a protease inhibitor cocktail and PMSF on ice for $15 \mathrm{~min}$. Lysates were centrifuged at $14,000 \mathrm{x}$ for $15 \mathrm{~min}$ at $4^{\circ} \mathrm{C}$. To assess the interaction between SOX11 and FAK, the supernatant was incubated overnight at $4^{\circ} \mathrm{C}$ with SOX11 antibody (Abcam; cat. no. ab170916). Subsequently, $40 \mu 1$ protein A cross-linked to agarose beads (EMD Millipore; cat. no. IP05) were added, and the mixture was incubated for $1 \mathrm{~h}$ at $4^{\circ} \mathrm{C}$ with constant rotation. The beads were washed 6 times with ice-cold lysis buffer prior to the addition of SDS-PAGE sample buffer to each sample. The bound proteins were dissociated from the beads by heating at $92^{\circ} \mathrm{C}$ for $3 \mathrm{~min}$ before they were resolved on $10 \%$ SDS-gels using SDS-PAGE as described above. Western blot analysis was used to evaluate the expression of SOX11 and FAK as described above.

Luciferase assay. FAK promoter (from $+23 \mathrm{bp}$ to $-2,000 \mathrm{bp}$, NCBI) was amplified by PCR, and the SOX11 gene sequence was constructed and amplified by PCR (Addgene, Inc.). Primers of the FAK promoter were designed (upstream primer, 5'CGACGCGTCTGGCTAATTTTTTTG TATTTTTAGTAGAG3' and downstream primer, 5'CCG CTCGAGCCCGACACCGACCCGGGCTTC3'). The FAK promoter was then cloned into a pGL3-FAK-Promotrer-Luc vector and the SOX11 gene was cloned into a PCDNA vector plasmid. The vectors were then co-transfected into 293T cells with the vectors mentioned above. The assessment was divided into 4 groups as follows: i) The vector group, where cells were transfected with the vector and pRL-TK, which was used as the internal reference plasmid; ii) the SOX11 + PGL3 group, where cells were transfected (using Lipofectamine 2000 transfection reagent; lot no. 2103397, Invitrogen; Thermo Fisher Scientific, Inc.) with pcDNA-SOX11, pGL3 and pRL-TK; iii) the pcDNA + pGL3-FAKP group, where cells were transfected with pcDNA, pGL3-FAKP and pRL-TK; and iv) the pcDNASOX11 + pGL3-FAKP group, where cells transfected with pcDNASOX11, pGL3-FAKP and pRL-TK. The duration between transfection and activity measurement was $48 \mathrm{~h}$. There were 4 groups of cells transfected. A total of 3 repeated experiments were carried out in each group. In addition, the plasmid of Renilla luciferase was co-transfected as the control. In order to eliminate the influence of other factors on the accuracy of experimental results, Firefly luciferase and Renilla luciferase were detected twice, and the 2 values were divided. The final luciferase activity of the 4 groups was obtained by averaging the ratio results of 3 replicates. The luciferase activity was measured using a luciferase assay system (Promega Corporation). The expression of FAK mRNA was measured by RT-qPCR as described above.

Statistical analysis. All experiments were repeated 3 times independently, and data are presented as the means \pm the standard error of the mean. A one-way ANOVA followed by the Holm Bonferroni post hoc test was used to test differences between groups. $\mathrm{P}<0.05$ was considered to indicate a statistically significant difference.

\section{Results}

CS deteriorates the biological behaviors and increases the apoptosis of, and results in the downregulation of SOX11 and FAK expression in AT2 cells. Compared with the sham group, the mechanical stretching of the AT2 cells induced by CS resulted in a decreased invasion, migration and adhesion of the AT2 cells (Fig. 1). Flow cytometric analysis also revealed 
A

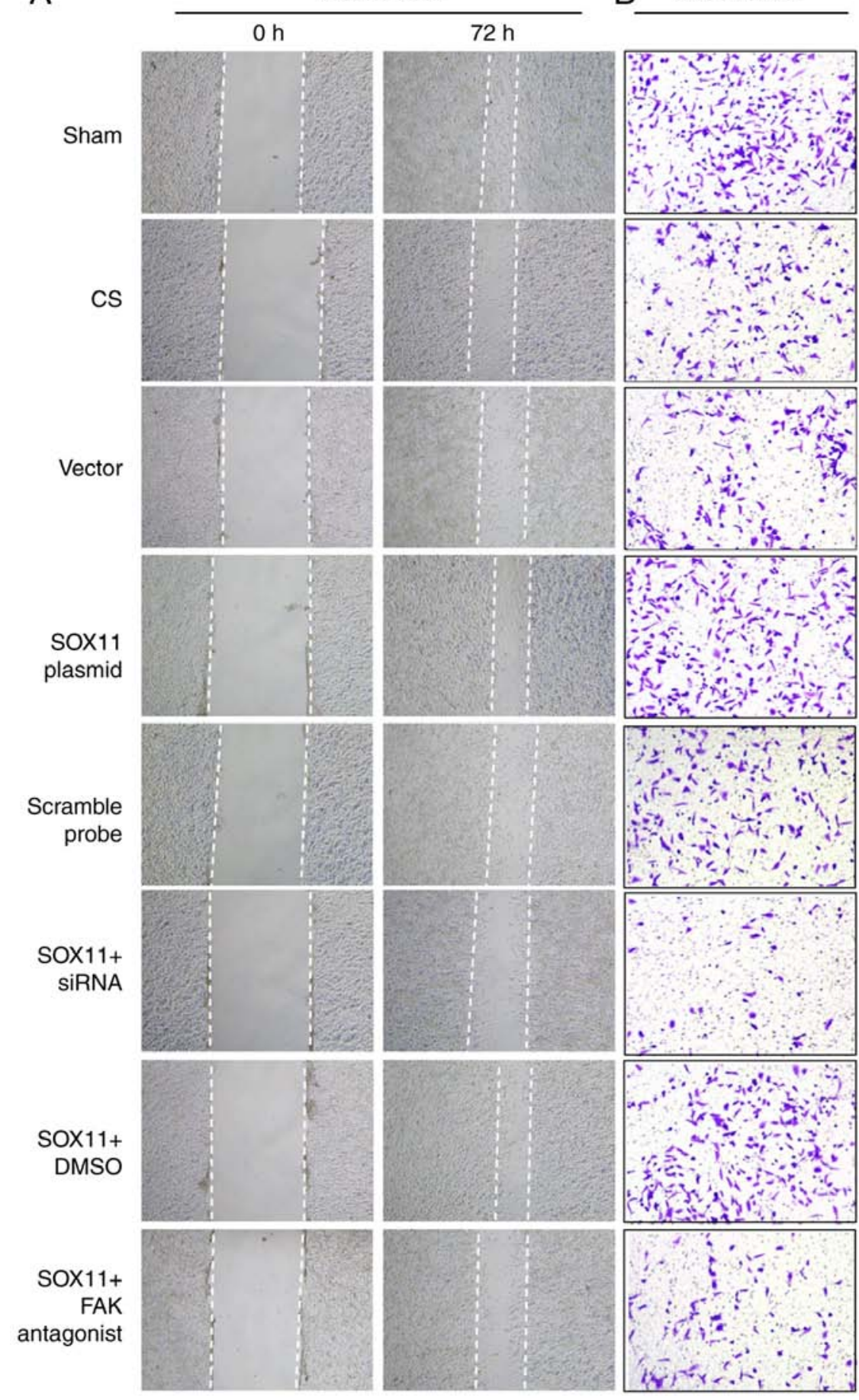

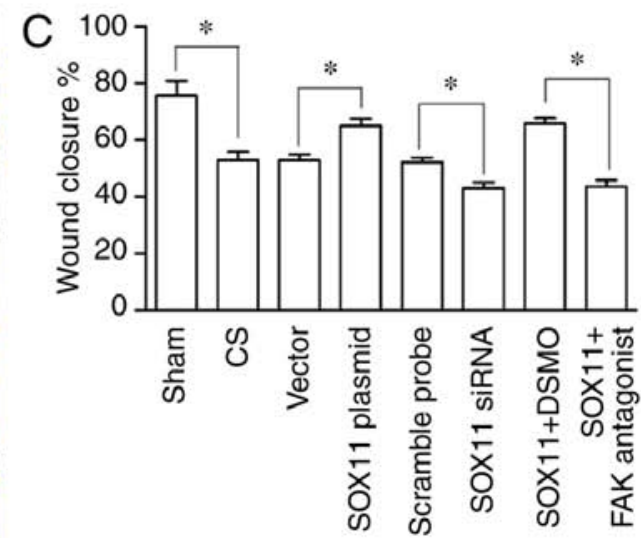

D

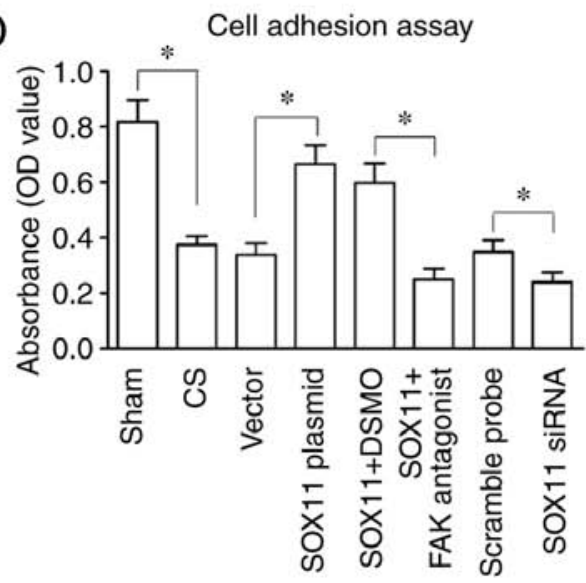

E

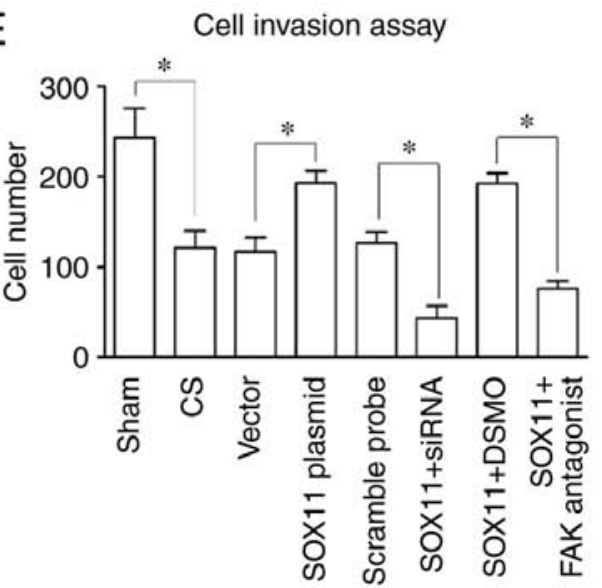

Figure 1. Changes in the biological behaviors of AT2 cells. (A and C) Wound healing, (B and E) invasion assays and (D) adhesion assay. The biological behaviors of the AT2 cells were deteriorated by CS, and the deterioration was reversed following overexpression of SOX11, or aggravated by knockdown of SOX11. Furthermore, the effects of SOX11 overexpression were inhibited by a FAK antagonist. (A) Magnification, x40; (B) magnification, x100. Data are presented as the means \pm standard error of the mean. ${ }^{*} \mathrm{P}<0.05$. AT2, alveolar type II; CS, cell stretch; SOX, Sex-determining gene on the Y chromosome related high mobility group box; FAK, focal adhesion kinase.

that the proportion of apoptotic AT2 cells increased following CS by $>2$-fold compared with the sham group (Fig. 2). The bar chart shows the percentages of late apoptotic cells (top right quadrant in the plots). RT-qPCR and western blot analysis revealed that SOX11 and FAK expression decreased following CS at the mRNA (Fig. 3A) and protein (Fig. 3B) level compared with the sham group.
Overexpression of SOX11 attenuates the effects of CS on AT2 cells. The efficacy of transfection and the effects of SOX11 overexpression on FAK expression were determined. Compared with the CS group, the mRNA (Fig. 4A and B) and protein (Fig. 4C and D) expression levels of SOX11 and FAK were significantly increased following transfection with SOX11 overexpression plasmid, suggesting that plasmid 

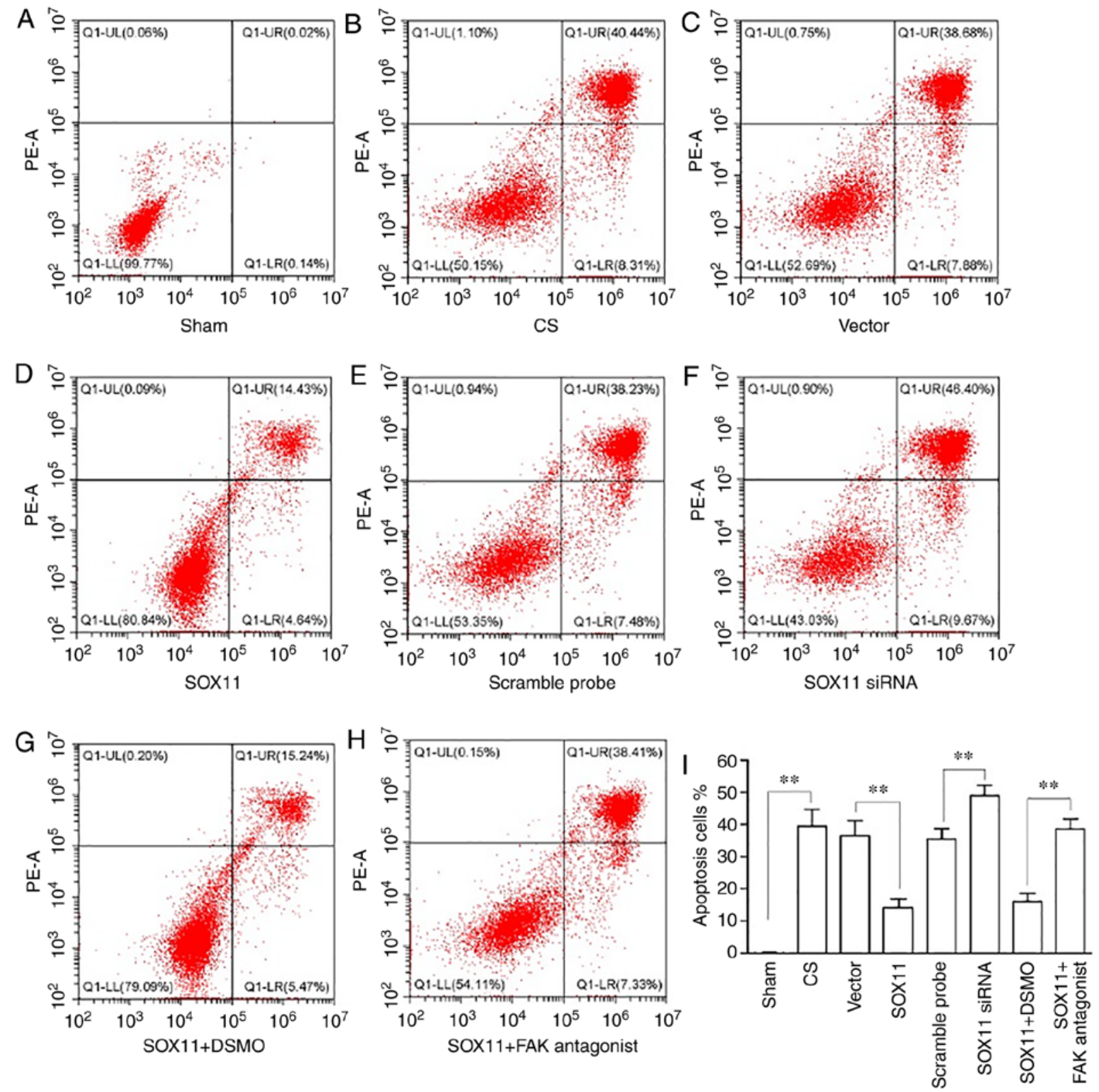

Figure 2. Apoptosis of AT2 cells in each group. (A-H) Flow cytometric analysis of cell apoptosis; (I) Quantification of cell apoptosis. The graph shows the percentage of late apoptotic cells (upper right quadarant in plots). CS significantly increased the apoptosis of AT2 cells. This increase in apoptosis was attenuated by SOX11 overexpression, and aggravated by SOX11 knockdown. In addition, FAK antagonism inhibited the effects of SOX11 overexpression. Data are presented as the means \pm standard error of the mean. ${ }^{* *} \mathrm{P}<0.01$. AT2, alveolar type II; CS, cell stretch; SOX, Sex-determining gene on the Y chromosome related high mobility group box; FAK, focal adhesion kinase.

transfection effectively upregulated the expression of SOX11 and FAK at both the gene and protein levels in the AT2 cells subjected to CS.

The effects of SOX11 overexpression on the deterioration of biological behaviors and the increased apoptosis of AT2 cells induced by CS were then assessed. The CS-induced decrease in the invasion, migration and adhesion of the AT2 cells was significantly attenuated following SOX11 overexpression (Fig. 1). Flow cytometric analysis indicated that the proportion of apoptotic cells decreased following SOX11 overexpression (Fig. 2). Furthermore, the protective effects of SOX11 overexpression against the deterioration of the biological behaviors and the apoptosis of AT2 cells mentioned above was prevented by treatment of the cells with a FAK antagonist, which was manifested by a decrease in invasion, migration and adhesion (Fig. 1), and an increase in the apoptotic rate (Fig. 2) of the AT2 cells in the SOX11 + FAK antagonist group compared with the SOX11 plasmid transfection group. The negative area (A/V-PI) indicates the proportion of normal AT2 cells. In the present study, the A/V-PI-fluctuated between $43-99 \%$ in the different groups (Fig. 2).

To illustrate the molecular mechanisms downstream of SOX11 and FAK, the changes in the expression levels of MMP7, p65, phosphorylated and total Akt, and caspase-3/8 at the protein level were assessed in the AT2 cells following CS. Western blot analysis revealed that compared with the CS group, transfection with SOX11 plasmid significantly increased the expressions levels of both phosphorylated and 

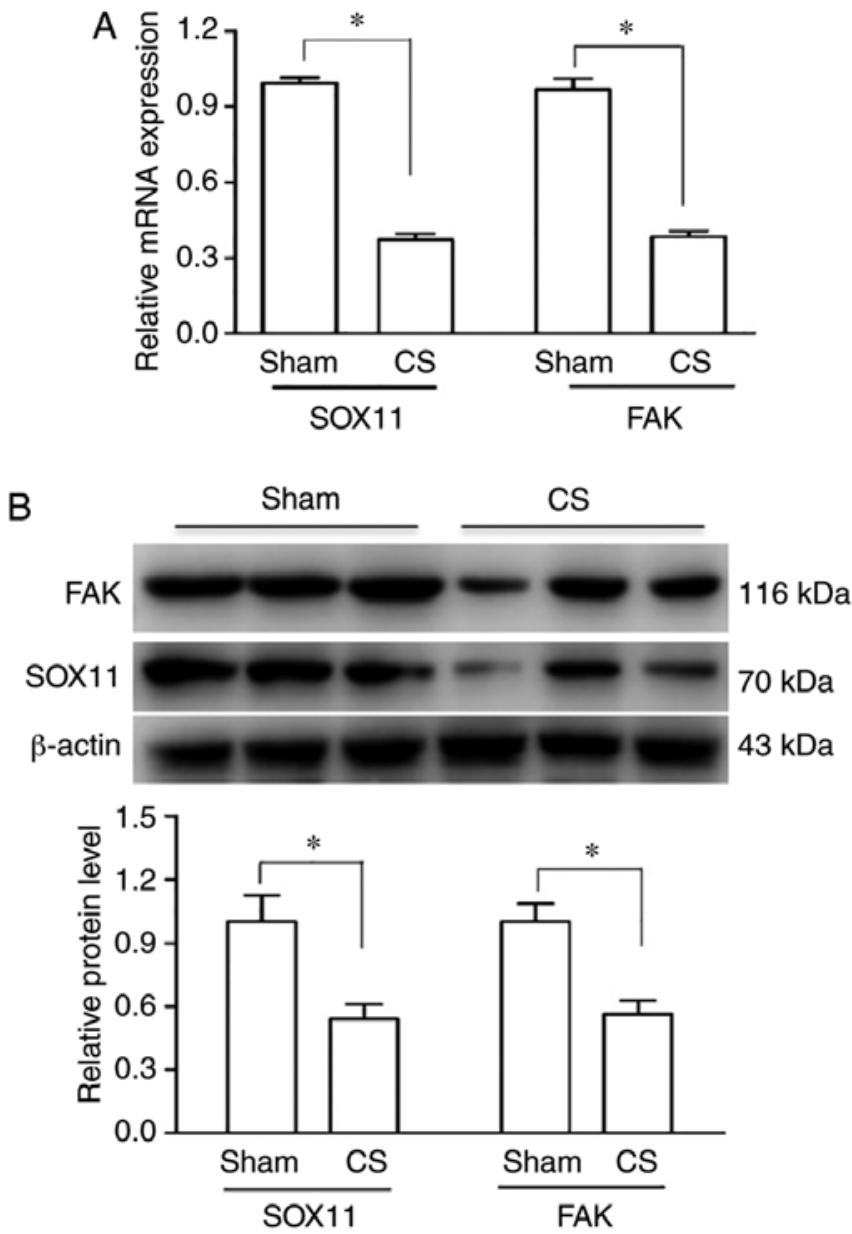

Figure 3. (A) Reverse transcription-quantitative PCR and (B) western blot analysis showing the downregulation of SOX11 and FAK at the mRNA and protein level in AT2 epithelial cells following CS. Data are presented as the mean \pm standard error of the mean. ${ }^{*} \mathrm{P}<0.05$. AT2, alveolar type II; CS, cell stretch; SOX, Sex-determining gene on the Y chromosome related high mobility group box; FAK, focal adhesion kinase.

total Akt, whereas the expression of MMP7 and p65 remained unaltered (Fig. 5). The overexpression of SOX11 resulted in a significant downregulation of caspase-3/8 expression when compared with the CS group. Following treatment with a FAK antagonist, the expression of caspase-3/8 significantly increased (Fig. 6) compared with the SOX11 overexpression group.

Transfection with SOX11 siRNA aggravates the deterioration of biological behaviors and increases apoptosis of AT2 cells induced by $C S$. The efficacy of SOX11 knockdown and the effects on FAK expression were then determined. Compared with scramble probe group, the expression levels of SOX11 and FAK at both the mRNA (Fig. 4A and B) and protein (Fig. 4C and D) level were significantly decreased in the SOX11 siRNA group, suggesting that SOX11 siRNA transfection effectively inhibited the expression of SOX11 and FAK in the AT2 cells subjected to CS.

Subsequently, the effects of SOX11 knockdown on the deterioration of biological behaviors and the apoptosis of AT2 cells induced by CS were investigated. It was found that the invasion, migration and adhesion (Fig. 1) of the
AT2 cells were significantly decreased following the knockdown of SOX11 compared with the CS group. Flow cytometric analysis indicated that compared with the cells subjected to CS, the knockdown of SOX11 significantly increased the proportion of apoptotic AT2 cells induced by CS (Fig. 2).

For the molecules downstream of SOX11 and FAK mentioned above, western blot analysis showed that knockdown of SOX11 significantly reduced the expression of both phosphorylated and total Akt (Fig. 5), and significantly increased the expression of caspase-3/8 (Fig. 6). This was accompanied by the deterioration of biological behaviors and an increase in the apoptosis of AT2 cells induced by CS following the knockdown of SOX11. The expression levels of MMP7 and p65 remained unaltered following transfection with SOX11 siRNA (Fig. 5).

SOX11 and FAK interact with each other. The results of Co-IP revealed that when a SOX11 antibody was incubated with agarose beads with AT2 cell lysates, SOX11 was detected in the bound protein, and its expression was markedly upregulated in the SOX11 overexpression group compared with the control group (Fig. 7A). Following incubation with a FAK antibody with the bound protein, FAK bands were also detected in the bound protein. The above-mentioned results suggested that SOX11 and FAK were both present in the bound protein (Fig. 7A). Notably, the expression of FAK was markedly increased in the SOX11 overexpression group compared with the control group (Fig. 7A). In order to validate whether an interaction exists between SOX11 and FAK, the AT2 cells lysates were incubated with a FAK antibody and agarose beads again, and similar results were observed as that with the SOX11 antibodies (Fig. 7B). The results of Co-IP suggested that SOX11 was bound with FAK and regulated the expression of FAK in AT2 cells.

To further confirm the promoting effect of SOX11 on FAK expression, a luciferase assay was performed using the 293T cells. It was found that transfection with the pGL3-FAK promoter increased (Fig. 8C and E), while transfection with pcDNA SOX11 had no effect (Fig. 8B and E) on the luciferase activity compared with the vector group (Fig. 8A and E). However, following co-transfection with pcDNA SOX11 and pGL3 FAK promoter, the luciferase activity was further significantly increased (Fig. 8D and E) compared with the vector group and pcDNA + pGL3-FAKP group. RT-qPCR analysis revealed that the mRNA expression of FAK significantly increased in the pcDNA SOX11 + pGL3 and pcDNA-SOX11 + pGL3-FAKP groups (Fig. 8F). These results suggest that SOX11 may enhance the expression of FAK at the transcriptional level.

\section{Discussion}

AT2 cells are the progenitor cells of alveolar epithelial cells and play an important role in maintaining alveolar integrity and normal function (19). Under normal conditions, AT2 cells produce pulmonary surfactant and transform into AT1 cells to repair lung injury and to prevent severe lung injury (20). An important feature of acute lung injury is the dysfunction of AT2 cells and the decrease in alveolar surfactant (21). 
A

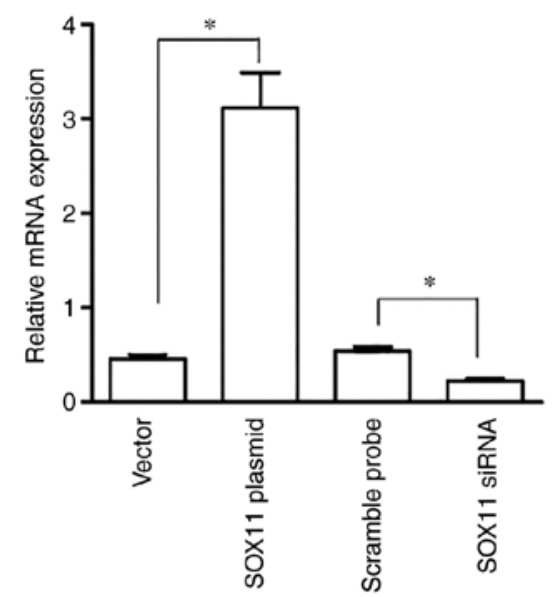

B

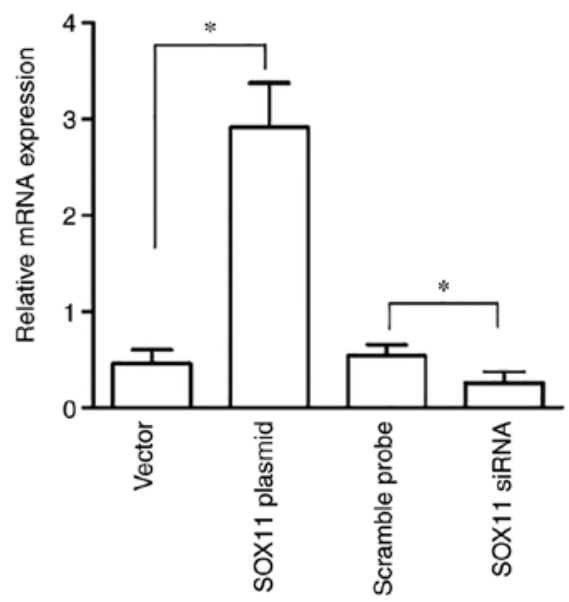

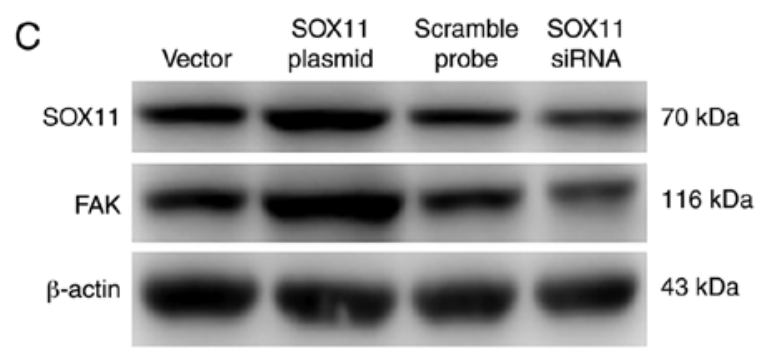
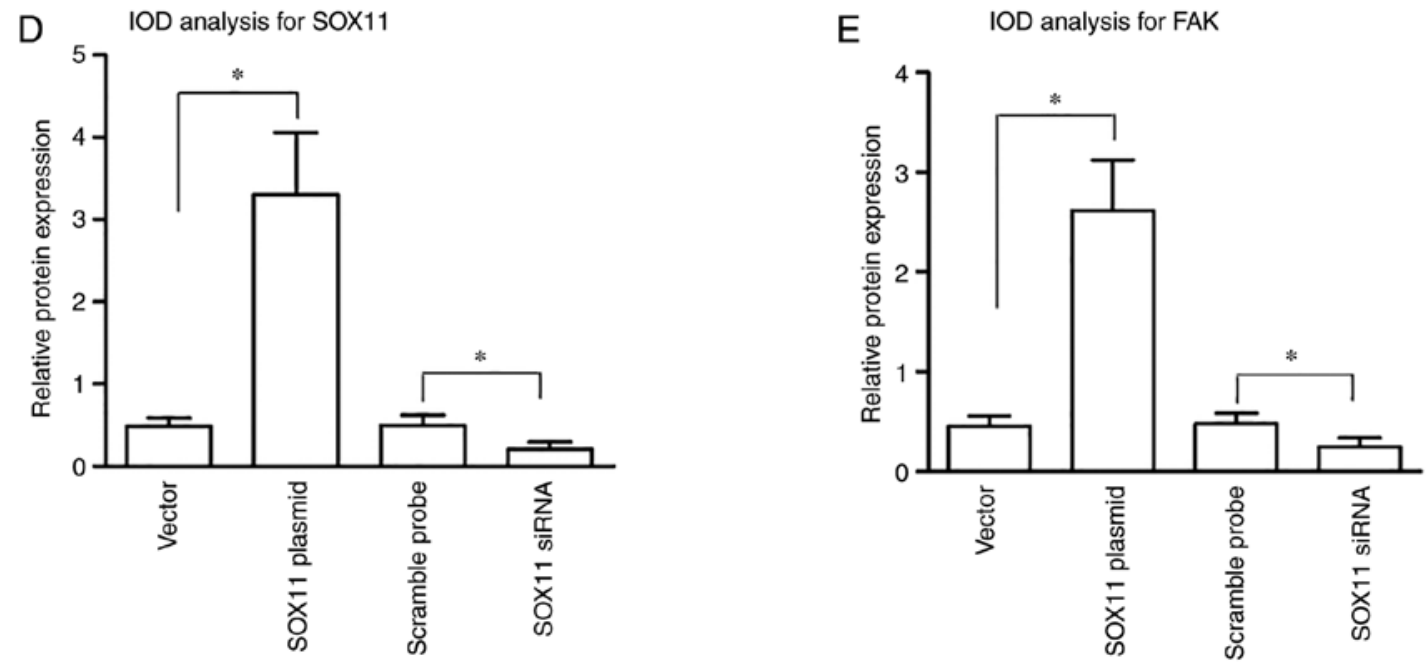

Figure 4. (A and B) Reverse transcription-quantitative PCR and (C-E) western blot analysis showing the effects of SOX11 overexpression and knockdown on the expressions of SOX11 and FAK at the mRNA and protein level in AT2 cells. Expression of SOX11 and FAK was significantly upregulated at both the mRNA and protein level following SOX11 overexpression. Knockdown of SOX11 decreased the levels of SOX11 and FAK. Data are presented as the means \pm standard error of the mean. ${ }^{*} \mathrm{P}<0.05$. AT2, alveolar type II; CS, cell stretch; SOX, Sex-determining gene on the Y chromosome related high mobility group box; FAK, focal adhesion kinase.

Mechanical stimulation, such as periodic mechanical stretching, can produce a series of adverse effects on AT2 cells, which induces apoptosis of AT2 cells (22), cell stress response (23), and even lead to cell death. Therefore, AT2 cell injury may be an important factor in the pathogenesis of VILI. A recent study by the authors demonstrated that impaired SOX11 and FAK signaling in the lungs was involved in the pathogenesis of VILI induced by hyper-mechanical ventilation in a mouse model (15). The present study further provides convincing evidence to indicate that the dysregulation of SOX/FAK signaling within AT2 cells is involved in the dysfunction of the biological behaviors and the increased apoptosis of AT2 cells using CS to directly simulate the shear stress of alveolar overstretching, a direct factor underlying the pathogenesis of VILI.

In the present study, it was demonstrated that the deterioration of biological behaviors and apoptosis of the AT2 cells induced by CS was accompanied by the downregulation of SOX11 and FAK expression. CS decreased the invasion, migration and adhesion of the AT2 cells, and increased apoptosis. It has been reported that mechanical 

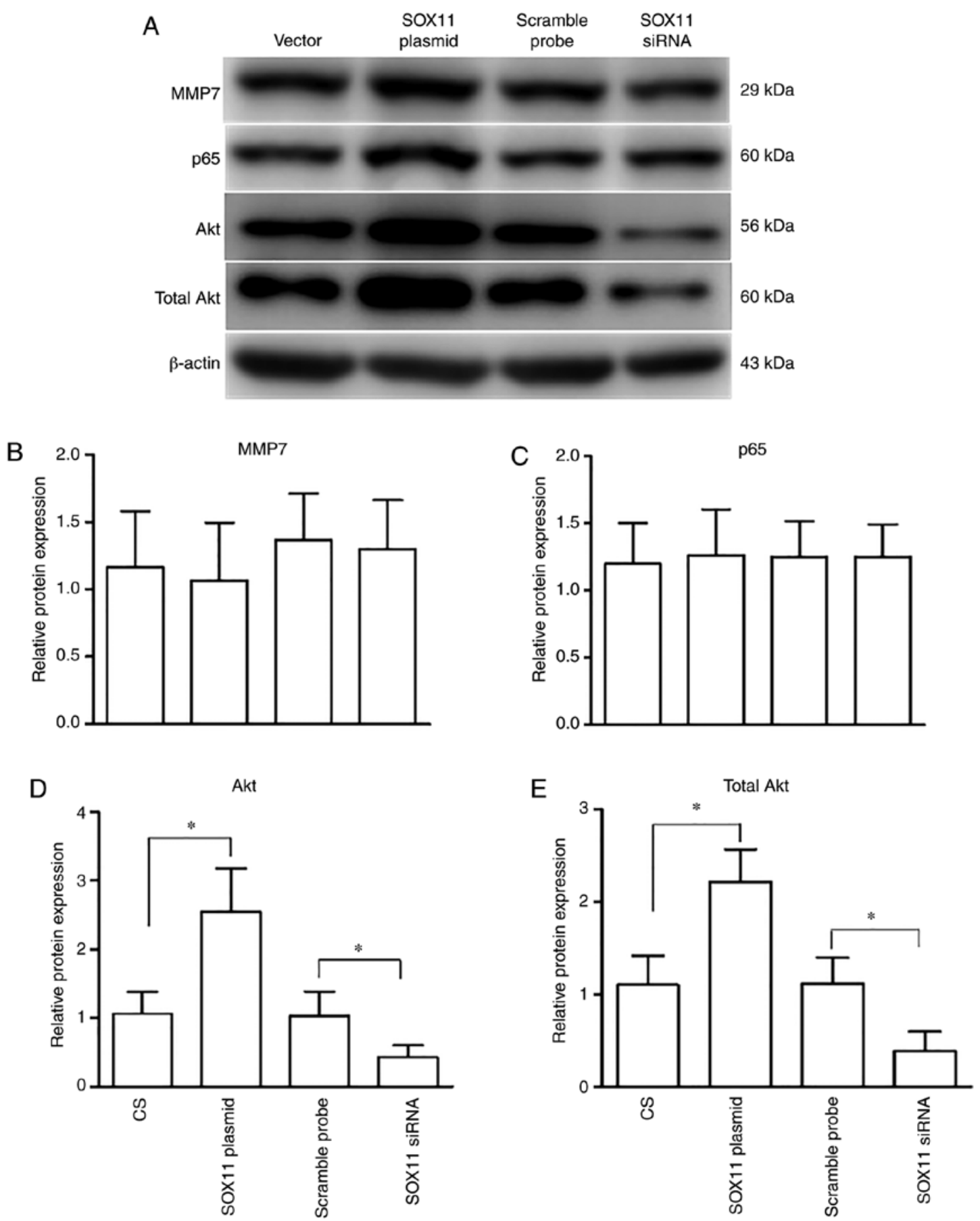

Figure 5. (A-E) Western blot analysis showing Akt, MMP7 and p65 protein expression in AT2 epithelial cells. Akt expression increased significantly following SOX11 overexpression, and significantly decreased following knockdown of SOX11. No changes in MMP7 and P65 expression were observed. Data are presented as the means \pm standard error of the mean. "P<0.05. AT2, alveolar type II; SOX, Sex-determining gene on the Y chromosome related high mobility group box; FAK, focal adhesion kinase; MMP7, matrix metalloproteinase 7.

injury to AT2 cells may be assessed based on their migratory and adhesive abilities, as well as the apoptotic rate $(24,25)$. The effect of CS on the apoptosis of AT2 encompasses the entire process of apoptosis, and in particular, is associated with the activation of the caspase pathway and the release of cytochrome $c$ in AT2 cells (22). Additionally, CS has been shown to decrease the viability of cells and the dysfunction of cell barrier function (26). These reports support the findings that the CS test can induce the deterioration of invasive, migratory and adhesive abilities, and increase the apoptosis of AT2 cells.
Notably, it was found in the present study that the expression of SOX11 and FAK at both the mRNA and protein expression level was downregulated in the AT2 cells that underwent CS, and this was accompanied by the deterioration of biological behaviors and increased apoptosis. As a member of the group C of SOX factors, SOX11 can regulate tissue development and remodeling, including lung development (8). The knockout of SOX11 in mice induces defects of neurogenesis and lung function $(3,27)$. FAK is known as a non-receptor tyrosine kinase. The activation of FAK can facilitate cell survival 

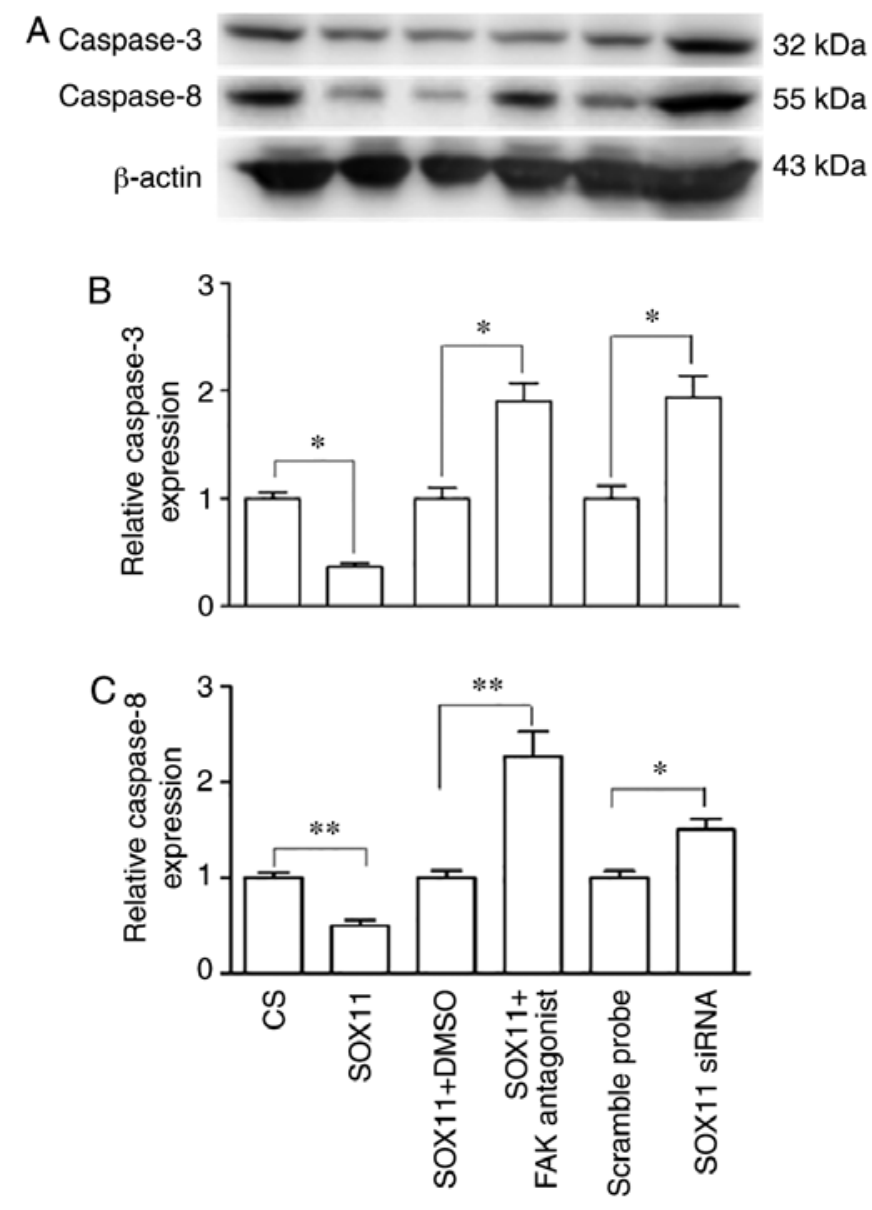

Figure 6. (A-C) Western blot analysis showing caspase-3/8 expression in AT2 cells. The overexpression of SOX11 inhibited, whilst the knockdown of SOX11 increased caspase-3/8 expression. Furthermore, FAK antagonism blocked the effect of SOX11 overexpression on caspase-3/8 expression. Data are presented as the means \pm standard error of the mean. ${ }^{*} \mathrm{P}<0.05,{ }^{* *} \mathrm{P}<0.01$. AT2, alveolar type II; SOX, Sex-determining gene on the Y chromosome related high mobility group box; FAK, focal adhesion kinase.

and attachment in culture, whereas the degradation of FAK promotes cell detachment and mobility (28). Desai et al (29) suggested that hyper-mechanical ventilation induced lung injury and decreased the levels of FAK phosphorylation (29). Ding et al (5) demonstrated a role of FAK signaling in determining the fate of lung epithelial cells. Therefore, the downregulation of SOX11 and FAK expression in the AT2 cells accompanied by AT2 mechanical injury in the present study indicates a clear possibility that the downregulation of SOX11 and FAK following CS may have been responsible for the pathogenesis of AT2 mechanical injury induced by CS.

Secondly, to further determine the role of SOX11 in CS-induced AT2 cell impairment, the effects of the overexpression and knockdown of SOX11 on the CS-induced impairments of the biological behaviors and apoptosis of AT2 cells were determined. It was found that following SOX11 overexpression, the effects of CS were attenuated. The knockdown of SOX11 aggravated the deterioration in the biological behaviors and further increased the apoptosis of AT2 cells induced by CS. These findings suggest that SOX11 dysregulation participates in CS-induced AT2 cell injury.
A

$\frac{\text { Input }}{\text { Control Sox11 }} \frac{\operatorname{lgG}}{\text { Control Sox11 }} \frac{\mathrm{IP}(\text { SOX11) }}{\text { Control Sox11 }}$

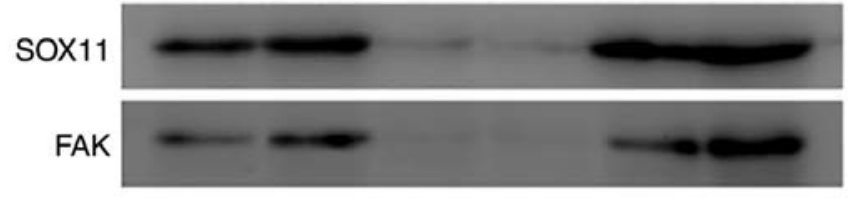

B
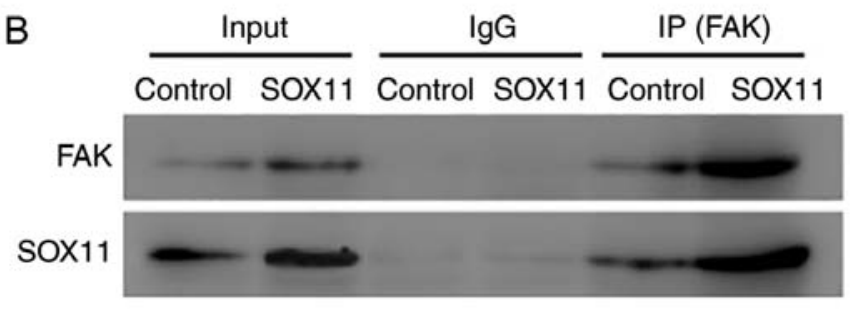

Figure 7. Co-IP showing the interaction between SOX11 and FAK. CoIP results revealed that when (A) a SOX11 antibody and agarose beads were incubated with the AT2 cells lysates, SOX11 was detected in the bound protein, and its expression was markedly upregulated when SOX11 was overexpressed compared with the control group. When a FAK antibody was incubated with the bound protein, FAK bands were also detected in the bound protein, and the expression of FAK was markedly increased in the SOX11 overexpression group compared with the control group, similar to the expression of SOX11. (B) When AT2 cell lysates were incubated with FAK antibody and agarose beads, similar results were observed as that with the SOX11. The results suggested that SOX11 was bound with FAK and regulated the expression of FAK in AT2 cells. Input, band from the lysate of AT2 cells; IgG, negative control for the SOX11 or FAK antibody. AT2, alveolar type II; IP, immunoprecipitation; SOX, Sex-determining gene on the $\mathrm{Y}$ chromosome related high mobility group box; FAK, focal adhesion kinase.

Researchers have demonstrated the mutually coordinated association between SOX11 and FAK in certain diseases. For example, in mantle lymphoma, the overexpression of SOX11 has been shown to increase the differentiation, proliferation and invasiveness of tumor cell through the FAK pathway (9). In pulmonary fibrosis, the expression of SOX11 and FAK has been shown to be increased, and the two proteins are primarily involved in pulmonary interstitial remodeling (30). In the present study, the expression of both SOX11 and FAK were downregulated simultaneously in the AT2 cells following CS. The overexpression of SOX11 increased FAK expression, whereas the knockdown of SOX11 decreased FAK expression both at mRNA and protein level. Furthermore, the attenuation of the deterioration of biological behaviors and the reduction of the apoptosis of AT2 cells following the overexpression of SOX11 was blocked by a FAK antagonist. Based on the above-mentioned results, it is thus suggested that FAK is a downstream molecule of SOX11, and is involved in the mechanisms through which SOX11 reduces mechanical injury of AT2 cells induced by CS.

Akt, also known as protein kinase B, is a serine/threonine protein kinase and plays a principle role in the survival and growth of cells. Studies have demonstrated the protective role of Akt in lung injury. For example, Akt activation has been shown to exhibit a protective function in oxidant-induced lung injury when adenoviral gene transfer was used (31). In addition, the activating of the expression of P13K/Akt using dexmedetomidine has been shown to 


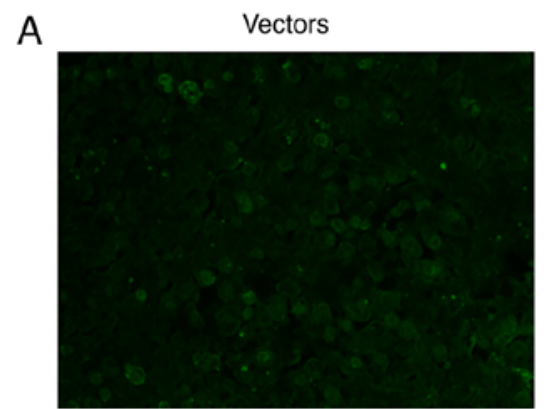

C

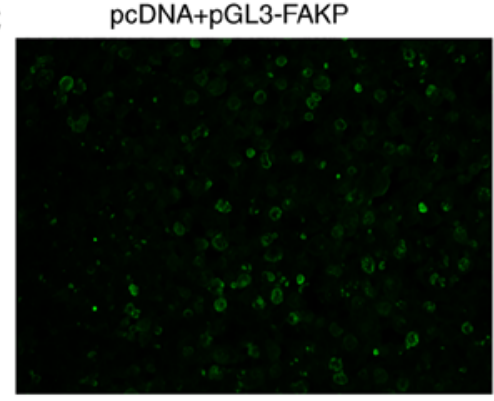

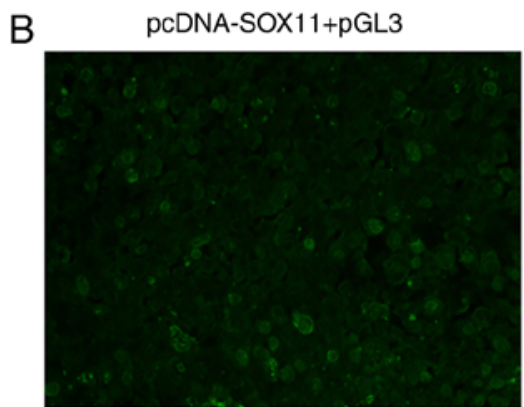

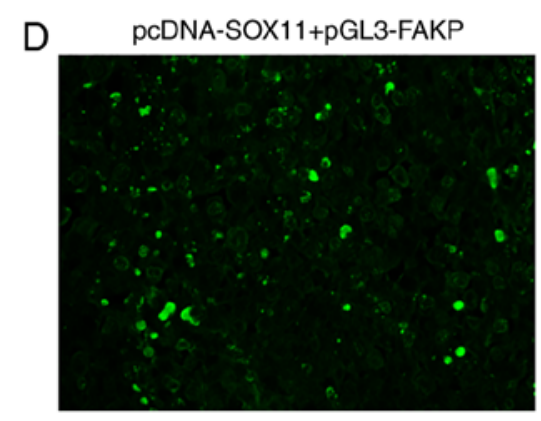

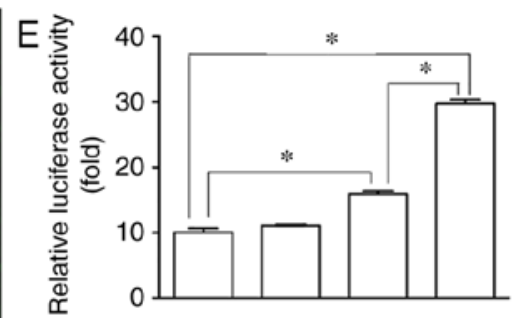

$\mathrm{F}$

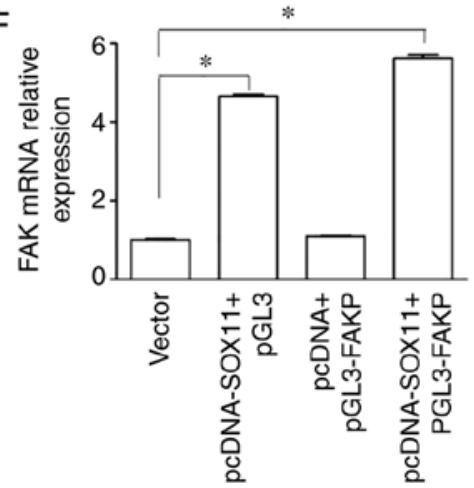

Figure 8. Luciferase assay showing the effects of SOX11 overexpression on luciferase activity and the expression of FAK mRNA in 293T cells in each group. It was shown that transfection with (C and E) pGL3-FAK promoter increased, while transfection with (B and E) pcDNA SOX11 had no effect on the luciferase activity compared with the vector group (A and E). (D and E) Following co-transfection with pcDNA SOX11 and pGL3 FAK promoter, the luciferase activity was further significantly increased compared with the vector group and pcDNA + pGL3-FAKP group. (F) RT-qPCR analysis revealed that the mRNA expression of FAK significantly increased in the pcDNA SOX11 + pGL3 and pcDNA-SOX11 + pGL3-FAKP groups. Data are presented as the means \pm standard error. ${ }^{*} \mathrm{P}<0.05$. SOX, Sex-determining gene on the $\mathrm{Y}$ chromosome related high mobility group box; FAK, focal adhesion kinase.

significantly reduce caspase-3/9 expression, and reduce lung injury and apoptosis following post-cardiopulmonary bypass (CPB) (32). In the present study, in addition to the effect on the expression of FAK, the overexpression of SOX11 significantly upregulated Akt expression, and the knockdown of SOX11 decreased Akt expression, including both the phosphorylated and total protein levels. FAK acts upstream of Akt-mediated signaling $(33,34)$, and FAK/PI3/Akt is a classical signaling pathway in cells (34). Thus, it was hypothesized that SOX11 can upregulate the expression of total and phosphorylated Akt via the FAK pathway. Similar findings have been reported previously. For example, Ji et al (34) demonstrated that FAK upregulate the expression of both total and phosphorylated Akt. Choi et al (35) revealed that drug-mediated intervention reduced the expression of both total and phosphorylated Akt. These studies support the hypothesis of the present study. As regards the determination of whether the upregulated levels of total Akt occurred through the regulation of gene transcription, at the protein level, or both, it is necessary to perform RT-qPCR to assess this. However, in the present study, a SOX11/FAK/Akt signaling pathway was hypothesized to mediate the protective effects on AT2 cells following CS. Further studies are required to investigate the effects of the inhibition of FAK on Akt expression and activity, and the effects of the inhibition of Akt on the SOX-mediated effects on mechanical injury to AT2 cells induced by CS, to provide additional support of the results of the present study.

As regards the mechanisms underlying the decreased apoptosis of AT2 cells following the overexpression of
SOX11, the overexpression of SOX11 inhibited, whereas the silencing of SOX11 increased the expression of caspase-3/8, respectively. Furthermore, the inhibition of caspase-3/8 following the overexpression of SOX11 was prevented by a FAK antagonist. Caspase-3 is a key protease involved in Fas-mediated apoptosis, and has been reported to act downstream of caspase-8 $(36,37)$. It has been demonstrated that FAK regulates apoptosis through the caspase pathway in alveolar epithelial cell injury (14). Zhang et al (38) also obtained similar results, demonstrating that the apoptosis of cardiac myocytes was also regulated via a FAK/Akt and caspase pathway (38). Thus, the inhibition of the caspase-3/8 pathway may be responsible for the anti-apoptotic effects induced by the overexpression of SOX11 and FAK following CS of AT2 cells in the present study.

A recent study by the authors demonstrated that the downregulation of SOX11 and FAK participated in the development of VILI in a mouse model (15). The present study assessed the biological behaviors and apoptosis of AT2 cells using a CS test, which directly mimics the effects of shear stress on cells, further demonstrating the role of activation of SOX11 and FAK in mechanical injury to AT2 cells, and the related molecular mechanisms involved in the process. Taken together, it can be concluded that the mechanical injury to AT2 cells, which results from overstretching during artificial ventilation using a ventilator may be an important factor in the pathogenesis of VILI. The downregulated expression of SOX11, FAK and Akt and may increase the apoptosis of AT2 cells. The upregulation of SOX11 and FAK may be a potential therapeutic target for the prevention and treatment of VILI in clinical practice. 


\section{Acknowledgements}

Not applicable.

\section{Funding}

The present study was supported by TianPu funding project (grant no. UF201414).

\section{Availability of data and materials}

The datasets used and/or analyzed during the present study are available from the corresponding author on reasonable request.

\section{Authors' contributions}

MF, TX and LL performed the experiments, performed the data analysis and writing the manuscript. NL participated in data analysis and figure editing. WL, MF, SF and JG conceived, designed the study, and contributed to data analysis. All authors read and approved the final manuscript.

\section{Ethics approval and consent to participate}

The ARRIVE guidelines for care and use of animals were adhered to in the present study. The animal experiments were approved by the Committee of Ethics on Animal Experiments of Hebei Medical University (approval no. ILAS-PL-2010-004). All efforts were made to minimize the suffering of animals and the number of the animals used.

\section{Patient consent for publication}

Not applicable.

\section{Competing interests}

The authors declare that they have no competing interests.

\section{References}

1. Chen L, Xia HF, Shang Y and Yao SL: Molecular mechanisms of ventilator-induced lung injury. Chin Med J (Engl) 131: $1225-1231,2018$

2. Gadi J, Jung SH, Lee MJ, Jami A, Ruthala K, Kim KM, Cho NH, Jung HS, Kim CH and Lim SK: The transcription factor protein Sox11 enhances early osteoblast differentiation by facilitating proliferation and the survival of mesenchymal and osteoblast progenitors. J Biol Chem 288: 25400-25413, 2013.

3. Mitamura Y, Nunomura S, Nanri Y, Arima K, Yoshihara T, Komiya K, Fukuda S, Takatori H, Nakajima H, Furue M and Izuhara K: Hierarchical control of interleukin 13 (IL-13) signals in lung fibroblasts by STAT6 and SOX11. J Biol Chem 293: 14646-14658, 2018.

4. Castillo SD, Matheu A, Mariani N, Carretero J, Lopez-Rios F, Lovell-Badge R and Sanchez-Cespedes M: Novel transcriptional targets of the SRY-HMG box transcription factor SOX4 link its expression to the development of small cell lung cancer. Cancer Res 72: 176-186, 2012.

5. Ding Q, Subramanian I, Luchhardt TR, Che P, Waghray M, Zhao XK, Bone N, Kurundkar AR, Hecher L, Hu M, et al: Focal adhesion kinase signaling determines the fate of lung epithelial cells in response to TGF- $\beta$. Am J Physiol Lung Cell Mol Physiol 312: L926-L935, 2017.
6. Gross CM, Kellner M, Wang T, Lu Q, Sun X, Zemskov EA, Noonepalle S, Kangath A, Kumar S, Gonzalez-Garay M, et al: LPS-induced acute lung injury involves NF- $\mathrm{BB}$-mediated downregulation of SOX18. Am J Respir Cell Mol Biol 58: 614-624, 2018.

7. Zhu Z, Dai J, Liao Y and Wang T: SOX9 protects against human lung fibroblast cell apoptosis induced by LPS through activation of the AKT/GSK3 $\beta$ pathway. Biochemistry(Mosc) 82: 606-612, 2017.

8. Sock E, Retting SD, Enderich J, Bösl MR, Tamm ER and Wegner M: Gene targeting reveals a widespread role for the high-mobility-group transcription factor Sox 11 in tissue remodeling. Mol Cell Biol 24: 6635-6644, 2004.

9. Balsas P, Palomero J, Eguileor Á, Rodriguez ML, Vegliante MC, Planas-Rigol E, Sureda-Gómez M, Cid MC, Campo E and Amador V: SOX11 promotes tumor protective microenvironment interactions through CXCR4 and FAK regulation in mantle cell lymphoma. Blood 130: 501-513, 2017.

10. Lee BY, Timpson P, Horvath LG and Daly RJ: FAK signaling in human cancer as a target for therapeutics. Pharmacol Ther 146: 132-149, 2015.

11. Yang S, Yip R, Polena S, Gricius J, Desai KJ, Sharma M, Ruby C, Gintautas J and Jerome H: Ischemia induced focal adhesion kinase cleavage in rat lung. Proc West Pharmacol Soc 47: 57-62, 2004.

12. Chen Q, Yi B, Ma J, Ning J, Wu L, Ma D, Lu K and Gu J: $\alpha 2$-adrenoreceptor modulated FAK pathway induced by dexmedetomidine attenuates pulmonary microvascular hyper-permeability following kidney injury. Oncotarget 7: 55990-56001, 2016.

13. Infusino GA and Jacobson JR: Endothelial FAK as a therapeutic target in disease. Microvasc Res 83: 89-96, 2012.

14. Wheaton AK, Agarwal M, Jia S and Kim KK: Lung epithelial cell focal adhesion kinase signaling inhibits lung injury and fibrosis. Am J Physiol Cell Mol Physiol 312: L722-L730, 2017.

15. Fang M, Fan S, Yao X, Liu N, Gao J, Wang Z, Xu T, Xian X and $\mathrm{Li}$ W: Transfection of Sox11 plasmid alleviates ventilator-induced lung injury via Sox 11 and FAK. Biochem Biophys Res Commun 512: 182-188, 2019.

16. Fang M, Liu N, Yao X, Xu T and Wang Z: Enhancement of FAK alleviates ventilator-induced alveolar epithelial cell injury. Sci Rep 10: 419, 2020.

17. Hide T, Takezaki T, Nakatani Y, Nakamura H, Kuratsu J and Kondo T: Sox 11 prevents tumorigenesis of glioma-initiating cells by inducing neuronal differentiation. Cancer Res 69: 7953-7959, 2009.

18. Livak KJ and Schmittgen TD: Analysis of relative gene expression data using real-time quantitative PCR and the 2(-Delta Delta C(T)) method. Methods 25: 402-408, 2001.

19. Castranova V, Rabovsky J, Tucher JH and Miles PR: The alveolar type II epithelial cell: A multifunctional pneumocyte. Toxicol Appl Pharmacol 93: 472-483, 1988.

20. Jansing NL, McClendon J, Henson PM, Tuder RM, Hyde DM and Zemans RL: Unbiased quantitation of alveolar type II to alveolar type I cell transdifferentiation during repair after lung injury in mice. Am J Respir Cell Mol Biol 57: 519-526, 2017.

21. Hallman M, Spragg R, Harrell JH, Moser KM and Gluck L: Evidence of lung surfactant abnormality in respiratory failure. Study of bronchoalveolar lavage phospholipids, surface activity, phospholipase activity, band plasma myoinositol. J Clin Invest 70: 673-683, 1982.

22. Edwards YS, Sutherland LM, Power JH, Nicholas TE and Murray AW: Cyclic stretch induces both apoptosis and secretion in rat alveolar type II cells. FEBS Lett 448: 127-130, 1999.

23. Vlahakis NE and Hubmayr RD: Invited review: Plasma membrane stress failure in alveolar epithelial cells. J Appl Physiol (1985) 89: 2490-2497, 2000.

24. Tschumperlin DJ, Oswari J and Margulies AS: Deformation-induced injury of alveolar epithelial cells. Effect of frequency, duration, and amplitude. Am J Respir Crit Care Med 162: 357-362, 2000.

25. Tschumperlin DJ and Margulies SS: Equibiaxial deformation-induced injury of alveolar epithelial cells in vitro. Am J Physiol 275: L1173-L1183, 1988.

26. Birukov KG, Jacobson JR, Flores AA, Ye SQ, Birukova AA, Verin AD and Garcia JG: Magnitude-dependent regulation of pulmonary endothelial cell barrier function by cyclic stretch. Am J Physiol Lung Cell Mol Physiol 285: L785-L797, 2003.

27. Guo Y, Liu S, Zhang X, Wang L, Zhang X, Hao A, Han A and Yang J: Sox 11 promotes endogenous neurogenesis and locomotor recovery in mice spinal cord injury. Biochem Biophys Res Commun 446: 830-835, 2014. 
28. Oliveira-Ferrer L, Hauschild J, Fiedler W, Bokemeyer C, Nippgen J Celik I and Schuch G: Cilengitide induces cellular detachment and apoptosis in endothelial and glioma cells mediated by inhibition of FAK/src/AKT pathway. J Exp Clin Caner Res 27: 86, 2008.

29. Desai LP, White SR and Waters CM: Mechanical stretch decreases FAK phosphorylation and reduces cell migration through loss of JIP3-induced JNK phosphorylation in airway epithelial cells. Am J Physiol Lung Cell Mol Physiol 297: L520-L529, 2009.

30. Skubitz KM and Skubitz AP: Gene expression in aggressive fibromatosis. J Lab Clin Med 143: 89-98, 2004.

31. Ahmed NN, Grimes A, Bellacosa TO, Chan TO and Tsichlis PN Transduction of interleukin-2 antiapoptotic and proliferative signals via Akt protein kinase. Proc Natl Acad Sci USA 94: 3627-3632, 1997

32. Li J, Dou X, Li D, He M, Han M and Zhang H: Dexmedetomidine ameliorates post-CPB lung injury in rats by activating the P13K/Akt pathway. J Invest Surg 33: 576-583, 2020.

33. Wang Z, Wang Z, Li G, Wu H, Sun K, Chen J, Feng Y, Chen C, Cai S, Xu J and He Y: CXCL1 from tumor-associated lymphatic endothelial cells drives gastric cancer cell into lymphatic system via activating integrin $\beta 1 / \mathrm{FAK} / \mathrm{AKT}$ signaling. Cancer Lett 385 : 28-38, 2017.

34. Ji Y, Wang Z, Li Z, Huang N, Chen H, Li B and Hui B: Silencing IGF-II impairs $\mathrm{C}$-myc and $\mathrm{N}$-ras expressions of SMMC-7721 cells via suppressing FAK/PI3K/Akt signaling pathway. Cytokine 90 44-53, 2017.
35. Choi AR, Kim JH and Yoon S: Sensitization of cancer cells through reduction of total Akt and downregulation of salinomycin-induced pAkt, pGSk3 $\beta$, pTSC 2 , and p4EBP1 by cotreatment with MK-2206. Biomed Res Int 2014: 296760, 2014.

36. Schlegel J, Peters I, Orrenius S, Miller DK, Thornberry NA, Yamin TT and Nicholson DW: CPP32/apopain is a key interleukin 1 beta converting enzyme-like protease involved in Fas-mediated apoptosis. J Biol Chem 271: 1841-1844, 1996.

37. Rieber M and Rieber MS: Correspondence re: S. Fulda et al, Betulinic acid triggers (Apo1/Fas)- and p53-indepedent apoptosis via activation of caspases in neuroctodernal tumors. Cancer Res. 57: 4956-4964, 1997. Cancer Res 58: 5876-5877, 1998.

38. Zhang R, Li L, Yuan L and Zhao M: Hypoxic preconditioning protects cardiomyocytes against hypoxia/reoxygenation-induced cell apoptosis via sphingosine kinase 2 and FAK/AKT pathway. Exp Mol Pathol 100: 51-58, 2016.

(1) $(9$ This work is licensed under a Creative Commons Attribution-NonCommercial-NoDerivatives 4.0 International (CC BY-NC-ND 4.0) License. 